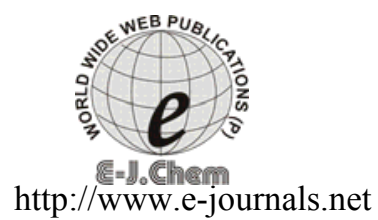

\title{
An Efficient Method for the Transthioacetalization of Acylals and Acetals under Mild Conditions
}

\author{
SEIED ALI POURMOUSAVI* MAJID HADAVANKHANI and ZAHRA ZINATI \\ School of Chemistry, \\ Damghan University, Damghan-3671641167, Iran \\ pourmousavi@du.ac.ir
}

Received 1 March 2011; Accepted 27 April 2011

\begin{abstract}
A rapid and efficient method for the transthioacetalization of acylals (1,1-diacetates) and acyclic and cyclic acetals is described. The reaction was carried out using 1-benzyl-4-aza-1-azoniabicyclo[2.2.2] octane tribromide (1 mol\%). The yield of the transthioacetalization was high and reaction conditions involve the use of acetonitrile as the solvent at room temperature; isolation is simple and the products are nearly pure.
\end{abstract}

Keywords: Acylal, 1,1-Diacetate, Transthioacetalization, Acetal, 1-Benzyl-4-aza-1-azoniabicyclo [2.2.2] octane tribromide

\section{Introduction}

Carbonyl functional groups often play important roles in the synthesis of complex organic molecules and a great deal of synthetic work has been done on the protection and masking of carbonyl compounds ${ }^{1}$. Acetals, acylals and thioacetals are the most widely used groups for masking a carbonyl compound. In spite of the difficulties associated with their removal, thioacetals are most often used because of their greater stability towards acidic conditions as compared to the corresponding $\mathrm{O}, \mathrm{O}$-acetals and acylals. In addition thioacetals are useful in organic synthesis as acyl carbanion equivalents in C-C bond forming reactions ${ }^{2}$. Moreover, $S, S$-acetals could be used as intermediates for the conversion of the carbonyl function to parent hydrocarbons ${ }^{3}$.

Transthioacetalization of acetals is a useful transformation for the preparation of thioacetals and in comparison with thioacetalization of carbonyl compounds, it is faster and cleaner. In the literature, several types of catalysts such as $5 \mathrm{M} \mathrm{LiClO}_{4}{ }^{4}, \mathrm{WCl}_{6}{ }^{5}$ trichloroisocyanuric acid, ${ }^{6} \mathrm{I}_{2},{ }^{7} \mathrm{MgBr}_{2},{ }^{8} \mathrm{TeCl}_{4},{ }^{9} \mathrm{ZrCl}_{4},{ }^{10} \mathrm{SiO}_{2} / \mathrm{SOCl}_{2}{ }^{11}$ and neutral koaline clay $^{12}$ were introduced previously for both thioacetalization and transthioacetalization processes. However, many of these reported methods require long reaction times, use of expensive and hazardous reagent and lack general applicability. On the other hand a few methods have also been reported for transthioacetalization of acylal ${ }^{6,13}$. 


\section{Experimental}

All Acetals and acylals were prepared by standard method. BABOT was prepared according to our previously reported method ${ }^{14}$. The thioacetals are known compounds and have been reported in the literature ${ }^{15}$. Yields refer to isolated pure products. The products were characterized by comparison with authentic samples (IR, ${ }^{1} \mathrm{H}$ NMR spectrum). All ${ }^{1} \mathrm{H}-\mathrm{NMR}$ spectra were recorded at $300 \mathrm{MHz}$ in $\mathrm{CDCl}_{3}$ relative to TMS $(0.00 \mathrm{ppm})$. IR spectra were recorded with a Perkin Elmer RXI spectrophotometer. Spectra of solids were recorded using $\mathrm{KBr}$ pellets.

\section{General procedure for the transthioacetalization}

To a solution of acylal or acetal $(5 \mathrm{mmol})$ and 1,2-ethanedithiol $(6 \mathrm{mmol})$ in acetonitrile $(5 \mathrm{~mL})$ was added BABOT $(0.05 \mathrm{mmol})$, and the resulting solution was magnetically stirred at room temperature. The progress of the reaction was monitored by TLC. After completion of the reaction, $10 \mathrm{~mL}$ of distillated water was added and the mixture was extracted with $\mathrm{CH}_{2} \mathrm{Cl}_{2}(3 \times 10 \mathrm{~mL})$ and the organic layer was washed with water $(10 \mathrm{~mL})$ and dried over anhydrous $\mathrm{Na}_{2} \mathrm{SO}_{4}$. Evaporation of the solvent gave almost pure product (s). Further purification, if necessary, was preceded by recrystallization in an appropriate solvent.

\section{The Spectral Data of Some Representative Products}

\section{2-Phenyl-1,3-dithiolane (Table 2, entry 1)}

IR (KBr) v $v_{\max }: 3043,2935,1580,1500,1490,1420,1380,700 \mathrm{~cm}^{-1} .{ }^{1} \mathrm{HNMR}\left(\mathrm{CDCl}_{3} 300\right.$ $\mathrm{MHz}): \delta$ 7.58-7.53 (2 H, m), 7.38-7.29 (3 H, m), $5.69(1 \mathrm{H}, \mathrm{s}), 3.58-3.52(2 \mathrm{H}, \mathrm{m}), 3.43-3.37$ $(2 \mathrm{H}, \mathrm{m}) \mathrm{ppm}$.

\section{2-(4-Chlorophenyl)-1,3-dithiolane (Table 2, entry 6)}

IR (KBr) v $v_{\max }: 3080,2920,1600,1470,1440,1375,1050,850,745 \mathrm{~cm}^{-1} .{ }^{1} \mathrm{HNMR}\left(\mathrm{CDCl}_{3}\right.$ $300 \mathrm{MHz}) \delta 7.70(2 \mathrm{H}, \mathrm{d}, \mathrm{J}=6.55 \mathrm{~Hz}), 7.25(2 \mathrm{H}, \mathrm{d}, \mathrm{J}=6.55 \mathrm{~Hz}), 5.60(1 \mathrm{H}, \mathrm{s}), 3.51-3.41$ (2 H, m), 3.36-3.29 (2 H, m) ppm.

\section{2-(3-Nitrophenyl)-1,3-dithiolane (Table 3, entry 2)} IR (KBr) $v_{\max }: 3086,2922,1579,1534,1344,1275,1076,822,722 \mathrm{~cm}^{-1} .{ }^{1} \mathrm{H}\left(\mathrm{CDCl}_{3} 300\right.$ MHz): $\delta 8.44(1 \mathrm{H}, \mathrm{s}), 8.16(1 \mathrm{H}, \mathrm{d}, \mathrm{J}=7.03 \mathrm{~Hz}), 7.87(1 \mathrm{H}, \mathrm{d}, \mathrm{J}=7.73 \mathrm{~Hz}), 7.52(1 \mathrm{H}, \mathrm{t}$, $\mathrm{J}=7.46 \mathrm{~Hz}), 5.71(1 \mathrm{H}, \mathrm{s}), 3.59-3.54(2 \mathrm{H}, \mathrm{m}), 3.48-3.43(2 \mathrm{H}, \mathrm{m}) \mathrm{ppm}$.

2-(4-Nitrophenyl)-1,3-dithiolane (Table 3, entry 4)

IR (KBr) $v_{\max }$ : 2930, 2853, 1603, 1521, 1424, 1352, 1317, 1291, 1245, 1112, 1015, 984, 876, 830, $784 \mathrm{~cm}-1 .{ }^{1} \mathrm{HNMR}\left(\mathrm{CDCl}_{3} 300 \mathrm{MHz}\right): \delta 8.17(2 \mathrm{H}, \mathrm{d}, \mathrm{J}=8.7 \mathrm{~Hz}), 7.66(2 \mathrm{H}, \mathrm{d}$, $\mathrm{J}=8.6 \mathrm{~Hz}), 5.65$ (s, $1 \mathrm{H}), 3.45-3.55$ (m, $2 \mathrm{H}), 3.37-3.43$ (m, $2 \mathrm{H}) \mathrm{ppm}$.

2-(2-Methoxyphenyl)-1,3-dithiolane (Table 3, entry 8)

IR (KBr) $v_{\max }: 3060,2945,2840,1600,1470,1370,1245,1175,1035,850,750 \mathrm{~cm}^{-1}$. ${ }^{1} \mathrm{HNMR}\left(\mathrm{CDCl}_{3} 300 \mathrm{MHz}\right): \delta 7.78(1 \mathrm{H}, \mathrm{d}, \mathrm{J}=7.66 \mathrm{~Hz}), 7.29-7.26(1 \mathrm{H}, \mathrm{m}), 6.99(1 \mathrm{H}, \mathrm{t}$, $\mathrm{J}=7.50 \mathrm{~Hz}), 6.89(1 \mathrm{H}, \mathrm{d}, \mathrm{J}=8.19 \mathrm{~Hz}), 6.10(1 \mathrm{H}, \mathrm{s}), 3.90(3 \mathrm{H}, \mathrm{s}), 3.49-3.45(2 \mathrm{H}, \mathrm{m}), 3.38-$ $3.35(2 \mathrm{H}, \mathrm{m}) \mathrm{ppm}$.

\section{Results and Discussion}

In continuation of our studies on developing a new method for transformation of organic functional groups ${ }^{16}$. Here we wish to introduce a simple and efficient method for transthioacetalization of acylals and acetals using a catalytic amount of 1-benzyl-4-aza-1azonia-bicyclo[2.2.2] octane tribromide (BABOT) (Scheme 1). 


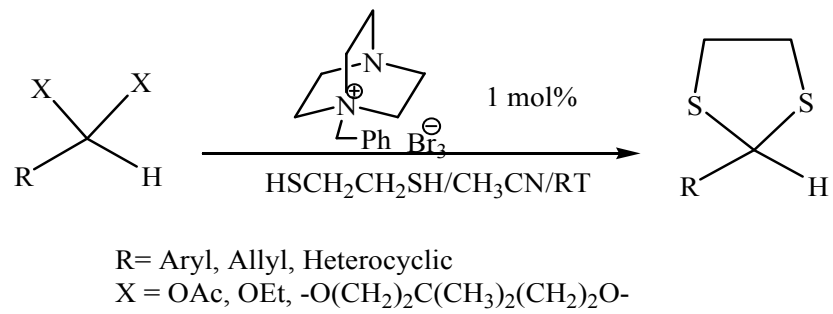

\section{Scheme 1}

Initially we attempted the transthioacetalization reaction of (3,4,5-trimethoxyphenyl) methanediacetate (1) with 1,2-ethanedithiol in the presence of BABOT (Scheme 2).

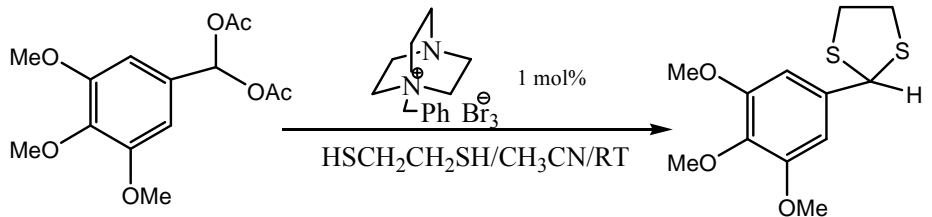

\section{Scheme 2}

The treatment of 1 equivalent of (1) with 1.2 equivalent of 1,2-ethanedithiol in the presence of BABOT $(1 \mathrm{~mol} \%)$ afforded the corresponding thioacetal in a short time in almost quantitative yield. To optimize the reaction conditions, we tried to convert (1) to its corresponding thioacetal in various solvents and also under solvent-free conditions (Table 1).

Table 1. Conversion of (1) to its corresponding thioacetal in different solvents and under solvent-free conditions in the presence of BABOT at $\mathrm{rt}^{\mathrm{a}}$

\begin{tabular}{cccc}
\hline Entry & Solvent & Time & Yield $^{\mathrm{b}}$ \\
\hline 1 & Methanol & $8 \mathrm{~h}$ & 80 \\
2 & Ethyl acetate & $5 \mathrm{~h}$ & 20 \\
3 & Acetonitrile & $30 \mathrm{~min}$ & 100 \\
4 & THF & $6 \mathrm{~h}$ & 40 \\
5 & Diethyl ether & $7 \mathrm{~h}$ & 50 \\
6 & Dichloromethane & $6 \mathrm{~h}$ & 65 \\
7 & Solvent Free & $8 \mathrm{~h}$ & 20
\end{tabular}

${ }^{a}(1) / 1,2$-ethanedithiol/BABOT (1:1.2:0.01 mmol). ${ }^{b}$ The yields refer to isolated pure products

As shown in Table 1, the yield of the reaction in acetonitrile as solvent is higher and the reaction time is shorter. Therefore, we employed the above conditions for transthioacetalization of acylals. In a control experiment, we observed that the reaction does not take place in the absence of BABOT. A wide range of acylals derived from aldehydes formed thioacetals with 1,2-ethanedithiol in high yields (Table 2). 
Table 2. Transthioacetalization of acylals using BABOT and 1,2-ethandithiol at $\mathrm{rt}^{\mathrm{a}}$

\begin{tabular}{|c|c|c|c|c|}
\hline Entry & Substrate & Product & Time, $\mathrm{h}$ & Yield $^{\mathrm{b}, \mathrm{c}}$ \\
\hline 1 & & & 3 & 93 \\
\hline 2 & & & 0.25 & 95 \\
\hline 3 & & & 6 & 93 \\
\hline 4 & & & 0.5 & 95 \\
\hline 5 & & & 3 & 90 \\
\hline 6 & & & 5 & 95 \\
\hline 7 & & & 0.5 & 93 \\
\hline 8 & & & 0.5 & 90 \\
\hline
\end{tabular}

${ }^{a}$ Yield referred to isolated pure products. ${ }^{b}$ Acylal/1,2-ethanedithiole/BABOT (1:1.2:0.01 mmol). ${ }^{c}$ The products were characterized from their spectral (IR and ${ }^{1} \mathrm{H} N M R$ ) and comparison to authentic samples

The role of BABOT is not clear but a plausible explanation is that BABOT reacts first with the 1,2-ethanethiol to generate $\mathrm{HBr}$, which may activate the acylal groups for further reaction The possible mechanism for transthioacetalization of acylal shown in Scheme 3. 


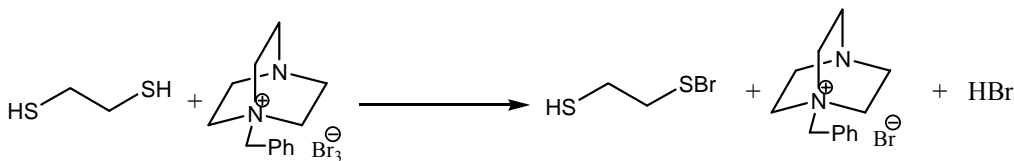<smiles>[R]C(OC(C)=O)OC(C)=O</smiles><smiles>[R]C1CCOC(C)C1OC(C)=O</smiles>

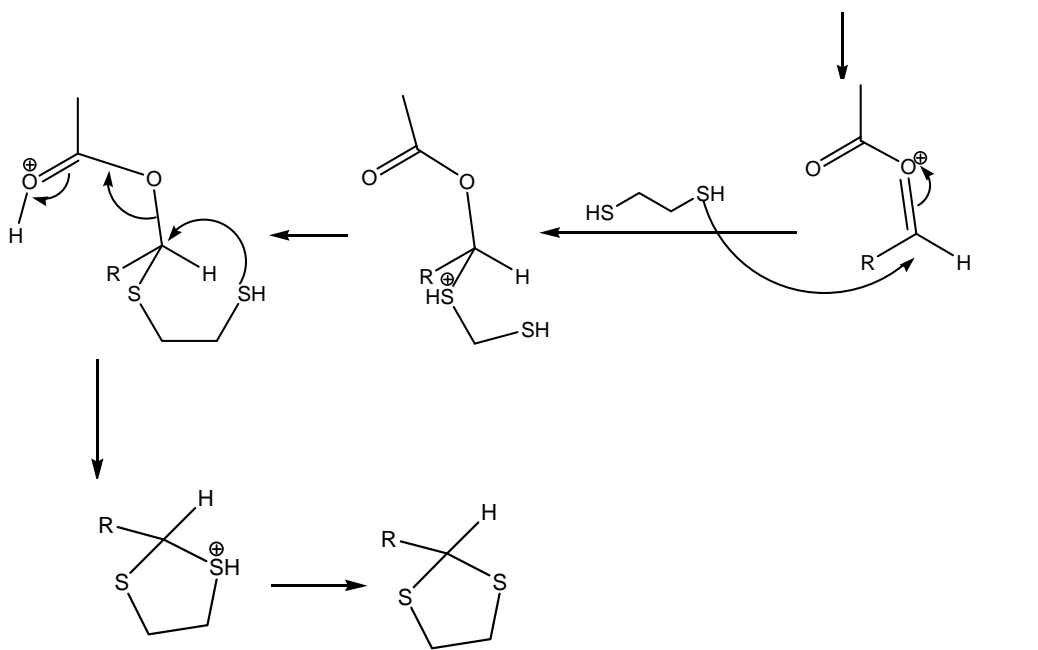

\section{Scheme 3}

In a similar manner an efficient transthioacetalization of $\mathrm{O}, \mathrm{O}$-acetals using BABOT has been achieved. A mixture of the benzaldehyde diethyl acetal and 1,2-ethanedithiol was allowed to react in the presence of BABOT $(1 \mathrm{~mol} \%)$ and acetonitrile at room temperature. The reaction mixture was worked-up and purification of the crude reaction mixture afforded the corresponding dithioacetal in 90\% yield (Scheme 4, Table 3).<smiles>CCOC(OCC)c1ccccc1</smiles>

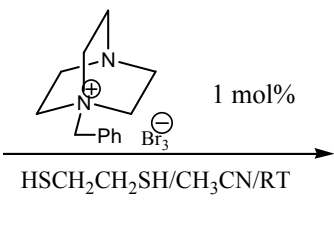

\section{Scheme 4}<smiles>c1ccc(C2SCCS2)cc1</smiles>

$90 \%$

This reaction revealed that transthioacetalization of the $\mathrm{O}, \mathrm{O}$-acetals occurred swiftly in a clean manner without any side product. The generality of the process was investigated with both acyclic acetals (diethyl acetals) and cyclic acetals (5,5-dimethy-1,3-dioxanes) bearing both electron- withdrawing and electron releasing substituents in the aromatic ring, the results are illustrated in Table 3 . In each case dithioacetal was obtained in good to excellent yields. 
Table 3. Transthioacetalization of acetals using BABOT and 1,2-ethandithiol at $\mathrm{rt}^{\mathrm{a}}$

\begin{tabular}{|c|c|c|c|c|}
\hline Entry & Substrate & Product & Time, $\mathrm{h}$ & Yield $^{b, c}$ \\
\hline 1 & & & 1.2 & 90 \\
\hline 2 & & & 3 & 85 \\
\hline 3 & & & 3 & 93 \\
\hline 4 & & & 3 & 87 \\
\hline 5 & & & 0.5 & 85 \\
\hline 6 & & & 0.65 & 85 \\
\hline 7 & & & 1.2 & 95 \\
\hline 8 & & & 0.5 & 95 \\
\hline 9 & & & 2 & 90 \\
\hline 10 & & & 0.5 & 91 \\
\hline
\end{tabular}

${ }^{a}$ Acetal/1,2-ethanedithiole/BABOT (1:1.2:0.01 mmol), ${ }^{b}$ Yield referred to isolated pure products. ${ }^{c}$ The products were characterized from their spectral (IR and ${ }^{1} \mathrm{H} N M R$ ) and comparison to authentic samples 
The reaction conditions are mild enough to perform these reactions in the presence of either acid- or base-sensitive substrates. This has been further substantiated by transthioacetalization an acid-sensitive substrate such as furfural diethylacetal as its dithioacetals derivative in an almost quantitative yield without the formation of any side products.

\section{Conclusion}

In conclusion, we have described a mild and efficient method for the transthioacetalization of acylals and acetals by 1,2-ethanedithiol in the presence of BABOT at r.t. in high yields. The notable advantage of this method is the requirement for minimum amounts of catalyst. The BABOT is prepared according to our previously reported method by an environmentally benign oxidation of bromide ion by potassium bromate ${ }^{15}$.

\section{Acknowledgment}

We gratefully acknowledge the funding support received for this project from the Damghan University IR Iran.

\section{References}

1. Greene T W and Wuts P G M, Protective Groups in Organic Synthesis $\left(2^{\text {nd }}\right.$ Ed., John Wiley and Sons, Inc: New York, 1991), pp 178-186.

2. (a) Corey E J and Seebach D, Angew Chem Int Ed Engl., 1965, 4, 1075-1076;

(b) Corey E J and Seebach D, Angew Chem Int Ed Engl., 1965, 4, 1077-1078;

(c) Corey E J and Seebach D, J Org Chem., 1966, 31, 4097-4099; (d) Seebach D, Angew Chem Int Ed Engl., 1979, 18, 239-258.

3. Pettit G R and Van Tamelen E E, Org React 1962, 12, 356-527.

4. Saraswathy V G and Sankararaman S, J Org Chem. 1994, 59(16), 4665-4670.

5. Firouzabadi H, Iranpoor N and Karimi B, Synlett., 1998, 739-740.

6. Firouzabadi H, Iranpoor N and Hazarkhani H, J Org Chem., 2001, 66, 7527-7529.

7. Samajdar S, Basu M K, Backer F F and Banik B K, Tetrahedron Lett., 2001, 42, 4425-4427.

8. Park J H and Kim S, Chem Lett., 1989, 18, 629-632.

9. Tani H, Masumoto K and Inamasu T, Tetrahedron Lett., 1991, 32, 2039-2042.

10. Firouzabadi H, Iranpoor N and Karimi B, Synlett., 1999, 319-320.

11. Firouzabadi H, Iranpoor N, Karimi B and Hazarkhani H, Synlett., 2000, 263-265.

12. Jnaneshwar K, Barhate N B, Sudalai A, Deshpande V H, Wakharkar R D, Gajare A S, Shingare M S and Sukumar R, J Chem Soc, Perkin Trans 1, 1998, 965-968.

13. Jin T-S, Sun G, Li Y-W and Li T-S, Synth Commun., 2004, 34(22), 4105-4110.

14. Pourmousavi S A, and Hadavandkhani M, J Sulfur Chem., 2009, 30, 37-45.

15. Hajipour A R, Pourmousavi S A, and Rouho A E, Phosphorus Sulfur Silicon Relat Elem., 2007, 182, 921-379.

16. (a) Pourmousavi S A, and Salehi P, Bull Korean Chem Soc., 2008, 29, 1332-1334;

(b) Pourmousavi S A and Zinati Z, Turk J Chem., 2009, 33, 385-392; (c) Pourmousavi S A and Salehi P, Acta Chim Slov., 2009, 56, 734-739. 


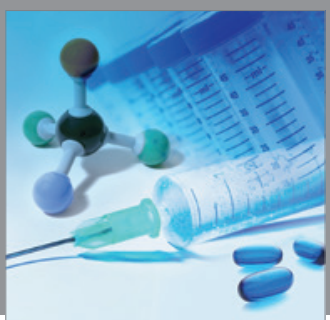

International Journal of

Medicinal Chemistry

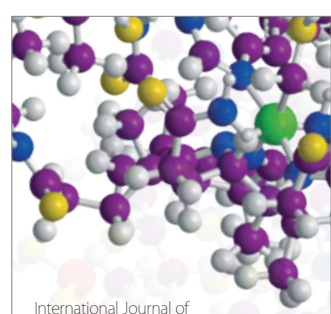

Carbohydrate Chemistry

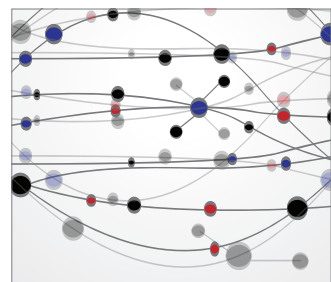

The Scientific World Journal
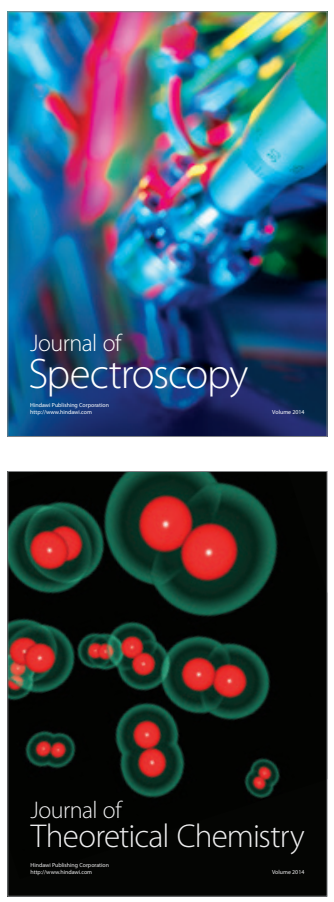
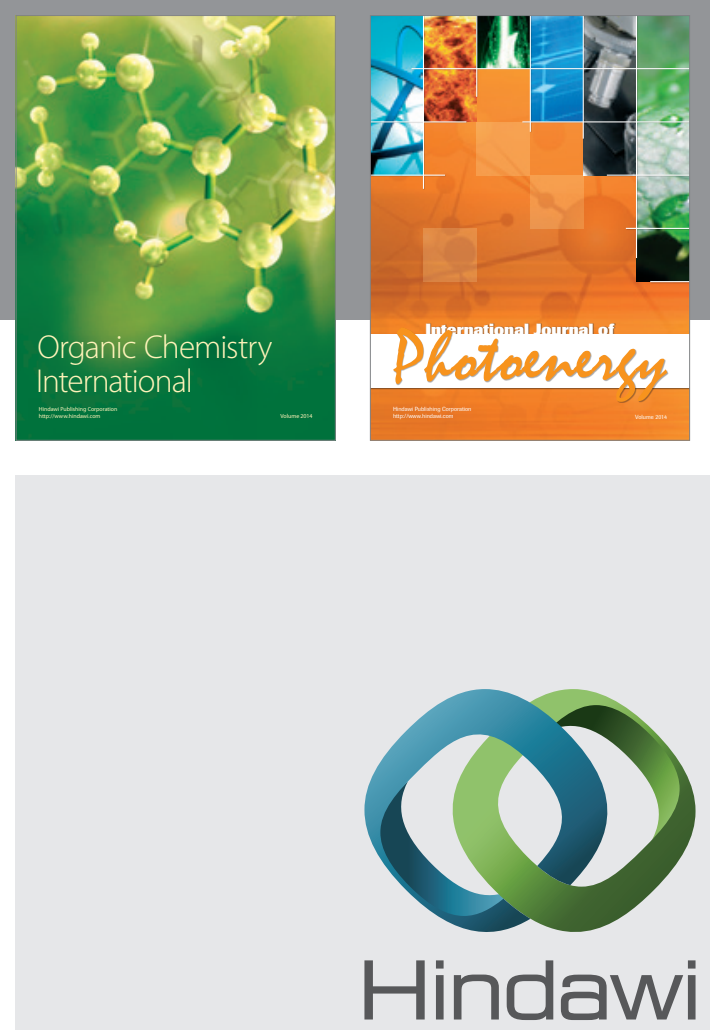

Submit your manuscripts at

http://www.hindawi.com
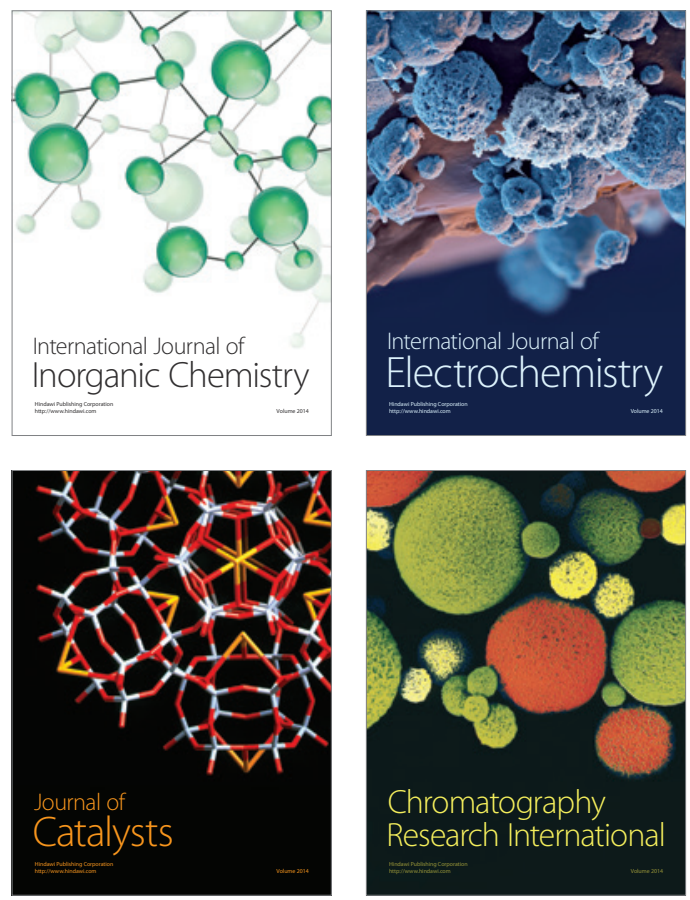
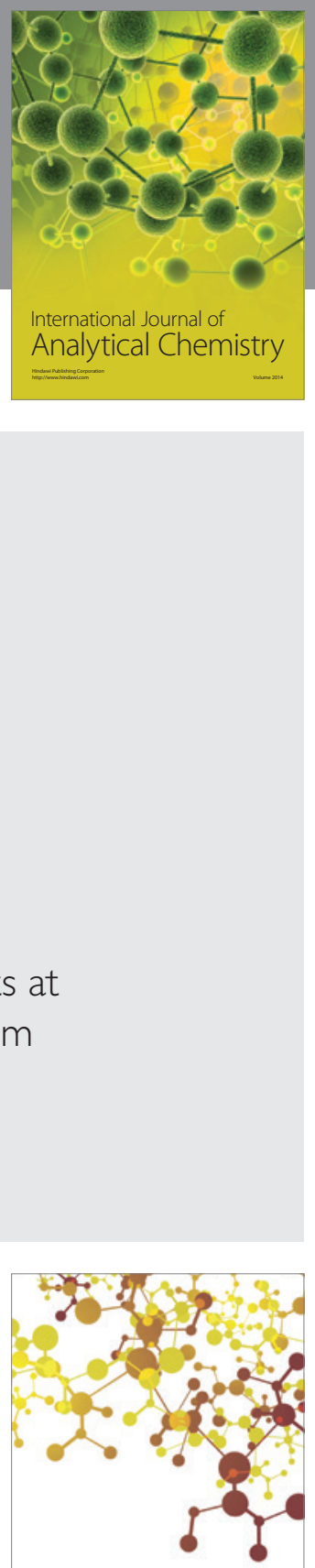

Journal of

Applied Chemistry
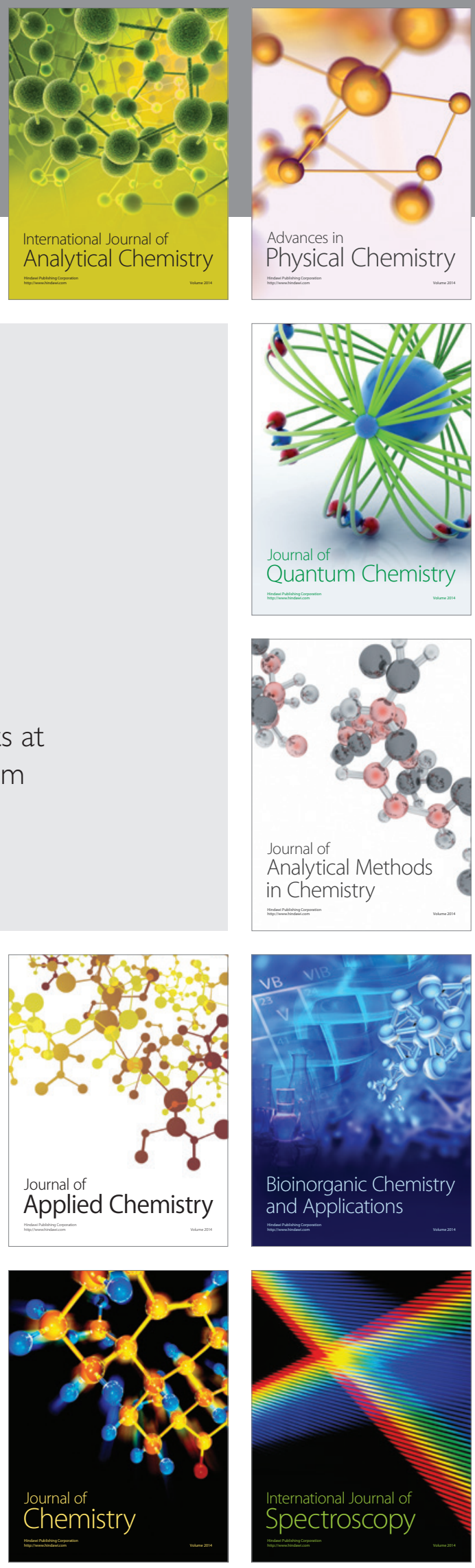